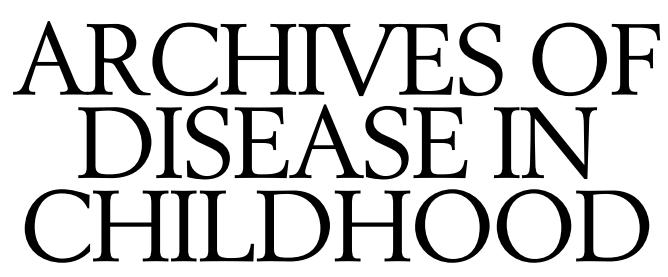

The Fournal of the Royal College of Paediatrics and Child Health

\title{
Annotations
}

\section{Rotavirus: a new vaccine for the UK?}

Each year it is estimated that group A rotavirus infection causes around 800000 deaths worldwide from gastroenteritis in children under 5 years of age. ${ }^{1}$ Symptoms usually accompany primary infection, which is followed by protection against subsequent symptomatic infection. ${ }^{2}$ For this reason, the peak attack rates for symptomatic rotavirus disease occur in children between 6 and 12 months of age. ${ }^{3}$

The development of rotavirus vaccines has focused mainly on the use of orally administered live attenuated rotaviruses from non-human hosts. A recent modification was the production of tetravalent vaccines containing "reassortant" strains of rotavirus (TV-RRV). ${ }^{4}$ These reassortants contain 10 genes from rhesus monkey strains and one gene that codes for human serotypes G1, G2, and G4; the rhesus rotavirus itself provides coverage for serotype G3. ${ }^{4}$ Efficacy studies in the USA, Finland, and Venezuela have demonstrated that TV-RRV provides good protection against severe rotavirus diarrhoea. ${ }^{5-7}$ In the USA, TV-RRV is now recommended for routine use by both the Advisory Committee on Immunizations Practices ${ }^{8}$ and the American Academy of Pediatrics. ${ }^{9}$ In spite of acknowledged need, the high cost of this vaccine puts it beyond the scope of most developing countries. ${ }^{10}$ In the developed world, however, TV-RRV is expected to be highly effective at preventing morbidity and mortality due to severe rotavirus diarrhoea, and could have a substantial economic impact from savings on the direct medical and social costs of caring for such children. ${ }^{112}$ The vaccine is currently going through licensing by the European Medicines Agency, and in the UK we will shortly have to decide whether the vaccine should be incorporated into our infant programme.

Before a decision on whether to introduce mass vaccination in the UK, estimates of the morbidity and mortality from rotavirus infection are required. One of the potential benefits of rotavirus vaccination would be to reduce the large numbers of admission for gastroenteritis each year. Unfortunately, it is difficult to estimate the annual numbers of admissions due to rotavirus from routine data in the UK. Hospital admissions are coded under the ninth revision of International Classification of Diseases (ICD-9), which has no specific code for rotavirus infection. In addition, as laboratory investigation is not always performed, routine data will always underestimate the true numbers of admissions due to rotavirus. ${ }^{13}$ To circumvent this, weekly data on laboratory confirmed infections and hospitalisations in North Thames were used to estimate admissions attributable to rotavirus during the winter seasonal increase of 1993-94. ${ }^{14}$ This approach suggested that rota- virus is responsible for about 17810 admissions each year in the UK-five admissions for every 1000 children under 5 years of age. To help confirm these findings, prospective hospital and community studies are underway in various parts of the UK.

A case series from Canada, ${ }^{15}$ and the excess of deaths from gastroenteritis in the winter in USA and Australia, ${ }^{16}{ }^{17}$ suggest that rotavirus can lead to death by dehydration in the developed world. In the USA, however, deaths from childhood diarrhoea have fallen in the past two decade ${ }^{17}$ and the number of such deaths are now very small in the UK. ${ }^{14}$

The present vaccine is designed to confer protection to severe disease with serotypes G1-G4, which are responsible for more than $90 \%$ of group A rotavirus infections in the developed world. ${ }^{18}$ More recent work, however, suggests a wider diversity, ${ }^{19}$ indicating the need for a systematic study before and after the introduction of vaccination: such a study is currently being coordinated by the Public Health Laboratory Service. Rotaviruses can evolve by genetic drift and genetic shift, and the possibility of zoonotic infection and of natural reassortment between animal and human strains has been suggested. ${ }^{20}$ No evidence of genetic change was found during the vaccine trials, ${ }^{21}$ but if high coverage is achieved, it is conceivable that the selection of rotavirus serotypes for which the vaccine is less effective may occur. As the vaccine protects poorly against mild or asymptomatic infection, endemic strains are expected to continue to circulate. For this reason, "escape" strains are unlikely to become established following the implementation of mass vaccination. Whether this assumption is correct should be answered within the next few years by the experience with mass vaccination in the USA.

As oral rotavirus vaccine can be given at the same time as diphtheria-tetanus-polio-Haemophilus influenzae type b and oral polio vaccine, mass vaccination could be relatively easy to implement in the UK. A substantial reduction in morbidity from childhood gastroenteritis would be expected, although the impact on mortality in the UK is likely to be limited. As parental perceptions of the severity of disease has always been a strongly associated with high coverage of vaccination, ${ }^{22}$ there has been concern that the vaccine would not be acceptable to UK parents. For the past two years, the Health Education Authority has been exploring parental attitudes to new vaccines as part of its regular research programme. Perhaps surprisingly, $70-75 \%$ of the mothers of children under 3 years old reported that they would probably or definitely be likely to have their child immunised (S Davis 
and Z Bozoky, personal communication, 1999). The task now is to establish the cost-benefit of vaccine introduction for the UK to convince the health care professionals and the vaccine policy makers.

Consultant Epidemiologist,

MARY RAMSAY

PHLS Communicable Disease Surveillance Centre,

61 Colindale Avenue, London NW9 5EQ, UK

1 Bern C, Martines J, de Zoysa I, Glass RI. The magnitude of the global problem of diarrhoeal disease: a ten-year update. Bulletin of the World Health lem of diarrhoeal disease: a ten-

2 Ward RL. Mechanisms of protection against rotavirus in humans and mice. f Infect Dis 1996;174:S51-8.

3 Rodriguez WJ, Kim HW, Brandt CD, et al. Longitudinal study of rotavirus infection and gastroenteritis in families served by a pediatric medical practice: clinical and epidemiologic observations. Pediatr Infect Dis $\mathcal{F} 1987$; 6:170-6.

4 Kapikian AZ, Hoshino Y, Chanock RM, Perez-Schael I. Efficacy of a quadrivalent rhesus rotavirus-based human rotavirus vaccine aimed at preventing severe rotavirus diarrhea in infants and young children. $\mathcal{F}$ Infect Dis 1996;174:S65-72.

5 Rennels MB, Glass RI, Dennehy PH, et al. Safety and efficacy of high-dose rhesus-human reassortant rotavirus vaccines - report of the National Multicenter Trial. United States Rotavirus Vaccine Efficacy Group. Pediatrics 1996;97:7-13.

6 Joensuu J, Koskenniemi E, Pang XL, Vesikari T. Randomised placebocontrolled trial of rhesus-human reassortant rotavirus vaccine for controlled trial of rhesus-human reassortant rotavirus vaccine

7 Perez-Schael I, Guntinas MJ, Perez M, et al. Efficacy of the rhesus rotavirusPerez-Schael I, Guntinas MJ, Perez M, et al. Efficacy of the rhesus rotavirus-
based quadrivalent vaccine in infants and young children in Venezuela. $N$ based quadrivalent vaccine in in

8 Recommended childhood immunization schedule-United States, 1999. MMWR Morb Mortal Wkly Rep 1999;48:8-16.

9 American Academy of Pediatrics. Committee on Infectious Diseases. Prevention of rotavirus disease: guidelines for the use of rotavirus vaccine. Pediatrics 1998;102:1483-91.
10 Rotavirus vaccines. WHO position paper. Weekly Epidemiological Record 1999;74:33-8.

11 Tucker AW, Haddix AC, Bresee JS, Holman RC, Parashar UD, Glass RI. Cost-effectiveness analysis of a rotavirus immunization program for the United States. FAMA 1998;279:1371-6.

12 Takala AK, Koskenniemi E, Joensuu J, Makela M, Vesikari T. Economic evaluation of rotavirus vaccinations in Finland: randomized, double-blind, placebo-controlled trial of tetravalent rhesus rotavirus vaccine. Clin Infect Dis 1998;27:272-82.

13 Parashar UD, Holman RC, Clarke MJ, Bresee JS, Glass RI. Hospitalizations associated with rotavirus diarrhea in the United States, 1993 through 1995: surveillance based on the new ICD-9-CM rotavirus-specific diagnostic code. F Infect Dis 1998;177:13-17.

14 Ryan MJ, Ramsay M, Brown D, Gay NJ, Farrington CP, Wall PG. Hospital admissions attributable to rotavirus infection in England and Wales. F Infect Dis 1996;174:S12-18.

15 Carlson JA, Middleton PJ, Szymanski MT, Huber J, Petric M. Fatal rotavirus gastroenteritis: an analysis of 21 cases. Am f Dis Child 1978;132:477-9.

16 Whitehead FJ, Couper RT, Moore L, Bourne AJ, Byard RW. Dehydration deaths in infants and young children. Am F Forens Med Pathol 1996;17:73-

17 Kilgore PE, Holman RC, Clarke MJ, Glass RI. Trends of diarrheal disease-associated mortality in US children, 1968 through 1991. FAMA 1995;274:1143-8.

18 Gentsch JR, Woods PA, Ramachandran M, et al. Review of G and P typing results from a global collection of rotavirus strains: implications for vaccine development. F Infect Dis 1996;174:S30-6.

19 Ramachandran M, Gentsch JR, Parashar UD, et al. Detection and characterization of novel rotavirus strains in the United States. F Clin Microbiol 1998;36:3223-9.

20 Nakagomi O, Nakagomi T. Interspecies transmission of rotaviruses studied from the perspective of genogroup. Microbiol Immunol 1993;37:337-48.

21 Jin Q, Ward RL, Knowlton DR, et al. Divergence of VP7 genes of G1 rotaviruses isolated from infants vaccinated with reassortant rhesus rotaviruses. Arch Virol 1996;141:2057-76.

22 Peckham C. National immunisation study: factors influencing immunisation uptake in childhood. Horsham: Action Research for the Crippled Child, 1989:1-46.

\section{Catheter ablation in paediatric arrhythmias}

The introduction of catheter ablation in the early 1990s was a major step forward in the management of arrhythmias. Before that most children were controlled with long term drug treatment, while a few underwent open heart surgery. Radiofrequency ablation now offers a non-surgical cure and has rapidly been adopted for the treatment of a wide variety of tachycardias. It has also redefined theories about the substrates and mechanisms of several tachycardias (so called "learning while burning").

\section{What is radiofrequency ablation?}

Catheter ablation is usually performed in conjunction with an invasive diagnostic electrophysiology study, which will identify the critical site in the tachycardia circuit or the origin of abnormal impulse formation. Radiofrequency ablation involves delivery of a high frequency $(500 \mathrm{kHz})$, low energy electric current to the critical area via an intracardiac catheter. The current induces a rise in tissue temperature at the point of contact with the heart and is similar, in a way, to low energy diathermy although the energy, frequency, and waveform are different. If the burn is precisely targeted it will produce a localised lesion to destroy the arrhythmia substrate. Energy delivery can be precisely controlled with catheter tip temperature feedback.

\section{Diagnosis and natural history of tachycardia}

The key to management of all tachycardias is a precise diagnosis. "Supraventricular tachycardia" is an inadequate term for a group of up to 12 different tachycardia mechanisms. Knowledge of the age of onset and analysis of 12 lead electrocardiograms recorded in tachycardia and in sinus rhythm will lead to a precise diagnosis in most cases. Knowing the diagnosis, one can define the natural history and plan treatment.
Most tachycardias in infancy are due to atrioventricular re-entry via an accessory pathway. In some the pathway functions anterogradely in sinus rhythm producing ventricular pre-excitation (Wolff-Parkinson-White syndrome) whereas in most the pathway conducts in a retrograde direction only and is known as "concealed". Most infants with atrioventricular re-entry tachycardia will have no further problems beyond the age of 6 or 12 months but in some the problem will persist or recur. Antiarrhythmic drug treatment is usually given for several months and then withdrawn. Those with persistent or recurrent tachycardia are managed as discussed below. Other tachycardias encountered in infancy include atrial ectopic tachycardia and atrial flutter, both of which will usually resolve, and permanent junctional reciprocating tachycardia and His bundle tachycardia, both of which are persistent. ${ }^{1}$

In school aged children the most common cause of "supraventricular tachycardia" is also atrioventricular re-entry via an accessory pathway. However, in this age group the problem will usually persist, so a long treatment strategy is required. In later childhood, atrioventricular nodal re-entry tachycardia is also seen relatively commonly and becomes the main differential diagnosis. ${ }^{2}$ Other arrhythmias such as atrial ectopic tachycardia, permanent junctional reciprocating tachycardia, and atrial flutter may also be encountered during school age. ${ }^{1}$ They are less common but require precise diagnosis from the ECG. All of these are likely to persist.

Ventricular tachycardias are less common in paediatric practice but may be encountered in infancy or childhood. Accurate diagnosis is required to define the natural history. Some types of ventricular tachycardia in infancy may resolve after drug treatment and a few of those encountered in childhood may be suitable for radiofrequency ablation. ${ }^{34}$ 


\section{Choice of treatment}

Most tachycardias in childhood are not life threatening, and decisions about treatment are therefore based on symptoms, taking into account the frequency, duration, and severity of attacks. One should also take account of the anxiety induced in children and their families, and the disruption caused by children being sent home from school or not being allowed to take part in school activities. The main treatment options are long term drug control and radiofrequency ablation. The choice is made by balancing the risks, inconvenience, cost, and benefit of each option. Although the introduction of each antiarrhythmic drug into paediatric practice has been accompanied by enthusiastic reports of efficacy, experience highlights the limitations including failure to control tachycardia, side effects, inconvenience, and potential for production of new arrhythmias. The most common indication for radiofrequency catheter ablation is patient choice, although failure of medical treatment is also a frequent factor. ${ }^{5-7}$

Garson and Kanter recently provided a cost effectiveness model for management of tachycardia. ${ }^{8}$ They compared the cost, morbidity, mortality, and efficacy of drug treatment, surgery, and radiofrequency ablation for a 5 year old child with symptomatic tachycardia associated with Wolff-Parkinson-White syndrome. They concluded that catheter ablation has a lower cost, mortality, and morbidity than either medical management or surgery and is the treatment of choice. They also concluded that several years of drug treatment before later radiofrequency ablation was a less desirable treatment plan. Their analysis and conclusions can be extrapolated to other forms of persistent tachycardia in childhood.

\section{Technique of catheter ablation}

The aim of catheter ablation of tachycardia in a patient with an accessory pathway is to destroy the accessory connection, thereby removing the arrhythmia substrate. ${ }^{9}$ Right sided and "septal" pathways are approached transvenously. Access to left sided pathways is usually gained transeptally (via a foramen ovale or transeptal puncture) but may also be retrograde via the femoral artery. In children with atrioventricular nodal reentry tachycardia (perhaps better regarded as atrio-nodal reentry) the arrhythmia circuit involves both the atrioventricular node and the adjacent atrium; anterior ("fast") fibres and posterior ("slow") fibres. The aim is to modify the tachycardia circuit by destroying part of the circuit yet leaving normal anterograde function of the node. ${ }^{2}$ The radiofrequency lesion is usually placed in the posterior atrio-nodal fibres with careful monitoring of atrioventricular conduction and of the response to the burn. ${ }^{2}$ Most other arrhythmias involve reentry circuits and catheter ablation targets the critical point in the circuit. ${ }^{1}$ A few originate from ectopic or automatic foci and the aim of ablation is to destroy the point source of such tachycardias. ${ }^{1}$

\section{Results of catheter ablation of common tachycardias}

As is the case with most newly introduced techniques, there was a learning curve in the early days of radiofrequency ablation, as shown by reports from single institutions or multicentre registries. ${ }^{10}{ }^{11}$ The Pediatric Electrophysiology Society maintains the largest register and reports the greatest experience. ${ }^{5}$ Contributors include large centres with great experience and smaller centres with less experience. The immediate success rates for accessory pathway ablation are around $85-90 \%$ and for atrioventricular nodal re-entry tachycardia $96 \%$. Catheter ablation may appear successful at the time when the accessory pathway has been "stunned" rather than destroyed so tachycardia may recur later. The registry reports about $75 \%$ freedom from recurrence at three years. Other large series report similar results. ${ }^{92-14}$ Experience in the United Kingdom is probably similar although there is considerable variation in institutional experience and no national registry or centralised data collection.

\section{Catheter ablation of other arrhythmias}

Most experience so far has been with catheter ablation of common arrhythmias, particularly accessory pathway tachycardias and atrioventricular nodal re-entry tachycardia. Some less common arrhythmias such as permanent junctional reciprocating tachycardia and atrial ectopic tachycardia are also particularly amenable to ablation with high success rates and rare complications. ${ }^{13}$ Some rare types of ventricular tachycardia are also effectively treated by catheter ablation. ${ }^{341516}$ The remaining challenge is in the management of atrial and ventricular arrhythmias late after repair of structural heart disease ${ }^{17}$ Those most commonly encountered are various types of atrial tachycardia or atrial flutter after atrial repair of transposition of the great arteries (Senning or Mustard operations) and atriopulmonary bypass for complex malformations with functionally one ventricle (Fontan operation and variants). Atrial tachycardias in such patients are particularly difficult to control with drugs and are probably associated with an increased risk of sudden death. Experience with catheter ablation of typical atrial flutter in structurally normal hearts led to enthusiasm that the procedure would also be effective in repaired congenital heart disease. The complexity of mapping has been greater than anticipated and results overall so far have been disappointing. This is partly due to the physical difficulty of mapping in such patients and partly due to the presence of more than one tachycardia circuit. It is to be hoped that the use of newly introduced computerised mapping techniques may lead to an advance in catheter ablation of such arrhythmias.

\section{Complications of radiofrequency ablation}

Significant complications of catheter ablation are rare. The main concern is overproduction of atrioventricular block by ablation of septal pathways close to the atrioventricular node or by radiofrequency modification of atrioventricular nodal re-entry tachycardia. The overall risk of atrioventricular block is quite low and is reported as around 1-5\% in modification of AV nodal tachycardia. ${ }^{512}{ }^{18}$ Damage to the mitral or aortic valves is rare. ${ }^{512}$ The risk is probably higher with a retrograde (transarterial) approach to left sided pathways than with an anterograde (transeptal) approach. Patients are usually anticoagulated during the procedure so embolic problems are rare. Death from catheter ablation is rare. Four deaths were reported in over 4000 children by the Pediatric Electrophysiology Society. ${ }^{5}$ Two deaths occurred after catheter ablation in infancy and two in children, one related to late ventricular perforation and one to early thrombotic occlusion of the origin of the left main coronary artery.

\section{Long term implications}

Most catheter ablation procedures are performed at the atrioventricular junction, which also contains the major epicardial coronary arteries. Early coronary artery damage is rare but long term follow up will be required before we can be confident that late coronary artery lesions are not produced, bringing their own problems. ${ }^{913} 19$ Other concerns include the long term effects of multiple applications of radiofrequency energy on myocardium or on atrioventricular valve function. ${ }^{9}{ }^{15}$ 


\section{Recommendations}

There are few if any indications for catheter ablation in infancy because most tachycardias can be controlled and many will resolve spontaneously. ${ }^{6}$

Taking into account the risks, disadvantages, and benefits of treatments on offer, catheter ablation is probably the treatment of choice for symptomatic tachycardias associated with accessory pathways and for atrioventricular nodal re-entry tachycardia in school age. Less common arrhythmias such as permanent junctional reciprocating tachycardia and atrial ectopic tachycardia need precise identification because they are also very suitable for catheter ablation. Catheter ablation is an option for some children with ventricular tachycardia after expert evaluation, and it is to be hoped that it will eventually have a significant role in the management of late postoperative atrial and ventricular arrhythmias.

CHRISTOPHER WREN

Consultant Paediatric Cardiologist,

Freeman Hospital, Newcastle upon Tyne NE7 7DN, UK

1 Saul JP, Walsh EP, Triedman JK. Mechanisms and therapy of complex arrhythmias in pediatric patients. F Cardiovasc Electrophysiol 1995;6:1129-84. 2 Prystowsky EN. Atrioventricular node reentry: physiology and radiofrequency ablation. PACE 1997;20:552-71.

3 O'Connor BK, Case CL, Sokoloski MC, Blair H, Cooper K, Gillette PC. Radiofrequency catheter ablation of right ventricular outflow tachycardia in children and adolescents. F Am Coll Cardiol 1996;27:869-74.

4 Simons GR, Klein GJ, Natale A. Ventricular tachycardia: pathophysiology and radiofrequency catheter ablation. PACE 1997;20:534-51.
5 Kugler JD, Danford DA, Houston K, Felix G. Radiofrequency catheter ablation for paroxysmal supraventricular tachycardia in children and adolescents without structural heart disease. Am f Cardiol 1997;80:1438-43.

6 Case, CL, Gillette PC, Oslizlok PC, Knick BJ, Blair HL. Radiofrequency catheter ablation of incessant, medically resistant supraventricular tachycardia in infants and small children. F Am Coll Cardiol 1992;20:1405-10.

7 Van Hare GF. Indications for radiofrequency ablation in the pediatric population. F Cardiovasc Electrophysiol 1997;8:952-62.

8 Garson A, Kanter RJ. Management of the child with Wolff-Parkinson-White syndrome and supraventricular tachycardia. $\mathcal{f}$ Cardiovasc Electrophysiol 1997;8:1320-6.

9 Gallagher JJ. Wolff-Parkinson-White syndrome: surgery to radiofrequency catheter ablation. PACE 1997;20:512-33.

10 Danford DA, Kugler JD, Deal B, et al. The learning curve for radiofrequency ablation of tachyarrhythmias in pediatric patients. Am $f$ Cardiol 1995;75:587-90.

11 Bubolz B, Case CL, McKay CA, O’Connor BK, Knick BJ, Gillette PC. Learning curve for radiofrequency catheter ablation in pediatrics at a single institution. Am Heart F 1996;131:956-60.

12 Calkins $\mathrm{H}$, Yong P, Miller JM, et al. Catheter ablation of accessory pathways, atrioventricular nodal reentrant tachycardia, and the atrioventricular junction. Circulation 1999;99:262-70.

13 Moak JP. Radiofrequency ablation of arrhythmias in the paediatric patient. Curr Opin Cardiol 1996;11:81-92.

14 Van Hare GF. Electrical/ablational therapeutic cardiac catheterization. Paediatr Cardiol 1998;19:95-105.

15 Silka MJ, Kron J. Radiofrequency catheter ablation for idiopathic right ventricular tachycardia: first, last or only therapy-who decides? $f$ Am Coll Cardiol 1996;27:875-6.

16 Vergara I, Wharton J. Ventricular tachycardia and fibrillation in normal hearts. Curr Opin Cardiol 1998;13:9-19.

17 Triedman JK, Saul JP, Weindling SN, Walsh EP. Radiofrequency ablation of intra-atrial reentrant tachycardia after surgical palliation of congenital heart disease. Circulation 1995;91:707-14

18 Schaffer MS, Silka MJ, Ross BA, Kugler JD. Inadvertent atrioventricular block during radiofrequency catheter ablation. Circulation 1996;94:321420

19 Wellens HJJ. Catheter ablation of cardiac arrhythmias. Circulation 1999;99: 195-7.

\section{Role of clinical ethics committees}

Most clinicians encounter ethical dilemmas, the resolution of which produces tensions within the multidisciplinary teams that deliver much contemporary health care. ${ }^{1}$ Despite the growth of medical ethics and publication of professional codes of practice ${ }^{2}{ }^{3}$ there is no clear consensus on how individuals, teams, and hospitals might obtain specific guidance in resolving the dilemmas they face. Indeed, current methods of resolving dilemmas may be ad hoc, unstructured, and subject to time constraints.

In North America health care ethics committees (HEC) have been established whose remit includes ethical debate and analysis of individual cases and topics, policy development, and education. ${ }^{5}$ Although $60 \%$ of US paediatric units have HECs, their role has been criticised and up to 33\% may be inactive. ${ }^{6} \mathrm{UK}$ experience with HECs is limited but interest is growing ${ }^{7}$ and a specific need has been identified in teaching and district general hospitals. ${ }^{48}$ In 1996 a clinical ethics forum (CEF) was established at Great Ormond Street Hospital NHS Trust in London in response to staff requests for a group having the following functions:

- Confidential, multidisciplinary analysis and discussion of cases and topics away from the acute clinical setting

- Informed contribution to the generation of guidelines for good ethical practice

- Education of health care professionals in health care ethics.

What follows is a brief critical account of the establishment, composition, and function of the CEF, which might be useful to others contemplating forming similar groups.

Establishment, composition, management, and accountability

The title "forum" was used to avoid the bureaucratic connotations of "committee", and to emphasise the intention to provide a facility for considered, informed, and reflective discussion. ${ }^{9}$ The forum's confidential, advisory, supportive, and non-prescriptive role safeguards clinical autonomy, protects the doctor-patient relationship, and facilitates participation and free discussion. Consultation is optional and there is no obligation to follow recommendations, although evidence suggests that those who seek advice would be likely to take it. ${ }^{10}$ Although accountable to the Trust Board, the forum's independence is important for its integrity and in gaining confidence of clinicians. Administrative support is essential for proper record keeping and has been provided from the research and development office at the Institute of Child Health.

The ideal size and composition of HECs depends on their intended functions. Prospective case review is best accomplished by small groups, ${ }^{11}$ but for more complex issues a larger membership is desirable, ${ }^{5}$ although group dynamics may be more problematic. ${ }^{12}$ The forum's membership includes physicians, surgeons, nursing staff, a social worker, and a chaplain, with $30 \%$ lay membership. The last's contribution is especially valuable because of differing perspectives and experience; lack of detailed scientific knowledge has not proved a barrier, rather it has emphasised the need for effective communication skills to presenting clinicians. Both chairman and vice chairman are elected by members; one of these officers is a lay member. No formal qualifications are required but $20 \%$ of serving members have formal training in moral analysis and two have postgraduate qualifications in ethics and law. No difficulties have been encountered in recruiting and retaining lay members but turnover of medical staff has been high, largely because of competing clinical or other commitments.

Some Trusts have developed HECs as part of a clinical ethics service ${ }^{7}$ and have employed clinical ethicists, usually 
as part of academic departments with responsibilities for undergraduate teaching. Clinicians appear to favour a committee approach and have preference for clinically trained ethicists. ${ }^{8}$ Some UK committees have included lawyers ${ }^{7}$; the forum does not although it has contacts with academic, legal opinion. The role of avoiding litigation, a feature of American committees, ${ }^{13}$ has not been one of the forum's functions.

The legal status of HECs has not been defined in the UK. By analogy with research ethics committees, HECs might be expected to:

- act in a reasonable fashion with due care

- have proper terms of reference

- be properly constituted (with arrangements for membership review)

- establish proper working procedures

- show accountability by publishing an annual report. ${ }^{14}$

The clinical ethics forum, which has written terms of reference and details of constitution, holds monthly minuted meetings and has published reports of activities.

\section{Case analysis and discussion}

A primary function of many American HECs is case analysis, either in response to issues raised by a specific case (post hoc analysis) or before critical decisions, such as withholding or withdrawing life sustaining treatment, are made (prospective analysis). Both forms satisfy requests for guidance, help prevent disputes within multidisciplinary teams, and separate ethical from technical or scientific issues. The prospective approach may:

- fail to respect clinical autonomy

- erode doctor-patient relationships

- risk undermining patients' interests in favour of those of the staff or the hospital

- enhance rather than prevent interprofessional dissent

- increase bureaucracy and reduce time available for patient care. ${ }^{15}$

The forum thought it wiser to begin with post hoc analysis because it is less threatening and intrusive. By emphasising confidentiality, asking that teams rather than individuals attend the forum, and underlining the voluntary nature of both consultation and following recommendations we believe that we overcame most of the above criticisms.

POST HOC ANALYSIS OF CASES AND TOPICS

Cases and topics were brought by invitation of the forum or request from staff; discussions usually lasted $1-11 \frac{1}{2}$ hours. Members of the Forum also facilitated independent discussion of cases with staff from units (such as paediatric or neonatal intensive care) where ethical dilemmas, many involving withholding or withdrawing treatment decisions, frequently arose. Over 20 cases were discussed in three years. They included:

- Parental refusal of procedures-for example, gastrostomy, thought to be in the child's best interests

- Conflicts over information that staff or parents thought a child ought to receive

- Management of behaviour potentially harmful to others in a disturbed adolescent after transplantation

- The action that should be taken when management of children in referring hospitals fell short of established good practice to their likely detriment

- Prescription of experimental treatment that the local health authority might not sanction

- The use of home total parenteral nutrition (TPN) in children with multiple medical and neurodevelopmental problems.
Broader topics discussed included xenografting in children and the use of covert video surveillance in the diagnosis of factitious illness.

We emphasised the need for teams to provide as comprehensive accounts of cases as possible, including medical facts, prognosis, results of psychosocial evaluation of the family, and the importance of sharing this information. Analysis of individual cases highlighted problems in communication due to lack of sufficient information, comprehension or time available to receive, absorb, and reflect on it. The feedback we received from teams was positive but we felt that we should interpret this with caution. ${ }^{9}$ Those present felt that the clinical and ethical complexity of issues for family and staff had been aired and that neither time available for patient care nor clinical freedom had been eroded.

In one particular group (the home TPN patients) discussions led to the establishment of a working party whose recommendations included a comprehensive psychosocial and ethical review before commencing home TPN. A small group, comprising the multidisciplinary home TPN team, a person with ethical expertise, and the parents meet following the psychosocial assessment to discuss whether home TPN is in the child's best interests. Time is given to reflect on the discussion before any final decision is made. This technique enabled us to fulfil the prospective case discussion function of American HECs with minimal problems. The forum has not been involved in other prospective critical decision making unless invited by clinical teams.

\section{Contribution to the generation of guidelines for good ethical practice}

Members of the forum have been involved both individually and collectively in developing guidelines and policies on consent and the use of medical illustration. The usual process involved smaller working groups co-opting relevant expertise before submitting a draft policy to the forum. Some institutional ethical guidelines-for example, the Royal College of Paediatrics and Child Health framework document ${ }^{16}$ and the British Medical Association consent policy, have used similar construction techniques with the ethics committees having overall responsibility. Constructing such guidelines has some parallels with clinical guidelines; the latter have established criteria for determining provenance, reliability, and evaluation, which we have tried to follow. ${ }^{17}$ Drafting multidisciplinary guidelines requires collaboration, communication, and interprofessional respect; implementation requires clear understanding of individual professional roles and responsibilities, and sense of co-ownership. Inevitably, policies draw criticisms from those who feel that they threaten clinical freedom, are too detailed, or strike the wrong balance between ethics and law. Guidelines that are developed in response to a particular clinical problem, such as the use of home TPN, are more likely to be accepted and used.

The forum has also contributed, with other relevant groups including hospital planning and management teams, to policies having a significant ethical component such as the philosophy of a chronic ventilation unit. Close collaboration with other interested groups is vital to prevent misunderstanding of roles and duplication of work such as risk management teams and consent, resuscitation committee and "do not resuscitate" orders, clinical governance, and good practice.

Any guidelines and policies are submitted to relevant hospital clinical and administrative groups for ratification. The forum has not rewritten national guidelines but has felt it reasonable to modify them where necessary to 
accommodate local needs. All ethical guidelines or policies must comply with current UK law.

\section{Education}

Disparity exists between the training in ethics and law that doctors and nurses receive; while ethics is an established core component of nursing curricula it has only recently achieved this status in medical education. ${ }^{18}$ There is no clear consensus on how ethics and law should be taught to postgraduates. Members of HECs should become familiar with ethical principles and theories, study relevant cases, policies, and legislation and have access to relevant literature. By developing expertise in practice HECs can undertake education of other professionals.

Case analysis based education may be opportunistic rather than structured but teaching programmes based on core curricula can be developed as part of a properly resourced ethics service. Members of the forum have given seminars, lectures, tutorials and contributed to postgraduate meetings and teaching courses. Biannual study days in ethics (topics: transplantation, children's rights, and adolescent medicine) have been held and have received good evaluations from participants. There is considerable future potential for innovative teaching activities, especially in the area of continuing education and involvement of older children in teaching.

\section{HECs, research, and research ethics committees}

Although research ethics committees (REC) rather than HECs undertake prospective ethical review of research both may (as at Great Ormond Street and Oxford) share members. HECs may engage in research that is reflective and analytical - for example, by examining claims that new treatments or techniques carry no fresh ethical implications. In consequence, they may articulate questions or concerns that can, with scientific arguments, be integrated into policy making. ${ }^{19}$ For example, the forum has considered arguments surrounding the proposal to remove, store, and manipulate gonadal tissue from prepubescent children at risk of sterility induced by cancer treatment.

The forum has also set out to ascertain the prevalence and nature of ethical perplexity among trust staff, and is developing techniques to audit and evaluate its role.

\section{The future of HECs in the United Kingdom}

There is lack of clarity over how ethical advisory services in UK hospitals should be provided or resourced. ${ }^{48}$ The clinical ethics forum has fulfilled most of its intended functions, albeit with limited resources. Its input has been valued; resistance has come mainly from those who fear erosion of clinical freedom and time for patient care, mistrust further bureaucracy, or doubt the cost effectiveness of a clinical ethics service. While the last point is important, there are powerful arguments for such a service; these may be summarised as follows.

Medical practice involves human activities where normative values, as much as scientific fact, technological capacity, and cost benefits, are important and are not the sole prerogative of clinicians. Increasing technological complexity and pressure on resources may have diminished its humanity. ${ }^{20}$ Ethics, perhaps via HECs, can represent the values and practices that define the hospital as a humanitarian community and ensure it remains aware of its moral rather than commercial responsibilities. ${ }^{21}$ Like the chorus in Greek drama HECs offer advice, historical perspectives, and support; they express moral concern and sympathy for those involved without usurping their roles. ${ }^{22}$ Finally, the process of ethical review confronts and acknowledges ambivalence and uncertainties in decision making rather than merely achieving an outcome. ${ }^{15}$

The moral purposes and values of modern medicine need examination, affirmation, and protection as much as ever. Properly constituted, resourced, and audited HECs, whether acting alone or as part of a clinical ethics service have a pivotal role in this process.

The following have all served as members of the forum: Professor A Aynsley-Green, Dr R Barlett, Dr B Bythe, Mr M de Leval, Dame Mary Donaldson, Mr D Drake, Ms A Elton, Mr D Fisher, Ms T Fleming, Dr R Gilbert, Dr A Goldman, Mr R Horne, Mr K Howse, Dr B Hurwitz, Dr V Larcher, Dr B Lask, Mrs J McCarthy, Mrs E Naughtie, Reverend R Partridge, Ms O Dr B Lask, Mrs J McCarthy, Mrs E Naughtie, Reverend R Partridge, Ms O
Sheils, and Dr R Trompeter. Their help, support and wise counsel is gratefully acknowledged.

GOSH Clinical Ethics Forum,

Research and Development Office,

Institute of Child Health,

Guilford Street, London WC1N 1EH, UK

1 McHaffie HE, Fowlie PW. Life and death decisions; doctors and nurses reflect on neonatal practice. Chesire: Hochland and Hochland, 1996.

2 Senate of Surgery Great Britain and Ireland. The surgeons duty of care. Guidance for Surgeons on ethical and legal issues. Senate of Surgery of Great Britain and Ireland, 1997.

3 General Medical Council. Good medical practice. London: GMC, 1998

4 Larcher VF, Lask B, McCarthy J. Paediatrics at the cutting edge; do we need clinical ethics committees? F Med Ethics 1997;23:245-9.

Fost N, Cranford RE. Hospital ethics committees - administrative aspects. fAMA 1985;253:2687-92.

6 Hoffman DE. Does legislating hospital ethics committees make a difference? Medicine and Healthcare 1991;19:105-18.

7 Meslin EM, Rayner C, Larcher V, Hope T, Savulescu J. Hospital ethics committees in the United Kingdom. London: HEC Forum 1996;8:346-54.

8 Slowther A, Underwood M. Is there a demand for clinical ethical advisory services in the UK? [letter] $\mathcal{F}$ Med Ethics 1998;24:207.

9 Siegler M. Ethics committees: decisions by bureaucracy. Hastings Cent Rep 1986;16:22-4.

10 Perkins HS. Clinical ethics consultations; reasons for optimism but problems exist. F Clin Ethics 1992;3:133-5.

11 Thornton J, Lillford R. Clinical ethics committees. BMF 1995;311:667-9.

12 Lo B. Behind closed doors. Promises and pitfalls of ethics committees. $N$ Engl f Med 1987;317:46-56.

13 Weiden P. Ethics by committee. N Engl f Med 1987;317:1418.

14 Kennedy I. Research ethics committees and the law. Foster CG, compiler. Manual for Research Ethics Committees. London: The Centre of Medical Law \& Ethics, Kings College, 1997.

15 Gillon R. Clinical ethics committees. Pros and Cons. F Med Ethics 1997;23: 203-4.

16 Withdrawing or withholding life sustaining treatment in children: a framework for practice. London: Royal College of Paediatrics \& Child Health, 1997.

17 Cluzeau F, Littejohns P, Grimshaw J, Feder G. Draft appraisal instrument for clinical guidelines. The development and implementation of clinical guidelines. Report from General Practice No 26. London: Royal College of guidelines. Report from General Prac

18 Consensus statement by teachers of medical ethics and law in UK medical schools. Teaching medical ethics and law within medical education: a model for the UK core curriculum. F Med Ethics 1998;24:188-92.

19 Trust and the bioethics industry [editorial]. Nature 1997;389:647.

20 Weatherall DJ. The inhumanity of medicine. Time to stop and think. BMF 1994;309:1671-2.

21 Blake DC. The hospital ethics committee and moral authority. London: HEC Forum, 1992;4:295-8.

22 King N. The ethics committee as a Greek chorus. London: HEC Forum, 1996;8:346-54. 